\title{
Overcoming physical distancing in online communities to create \\ human spaces for societal transformations
}

Felix Westermann, Linda Doll, Maren Duprés, Sofia Späth and

Petra Monika Schweizer-Ries

Electrical Engineering, Informatics and Sustainability, Bochum University of Applied Sciences, Bochum, Germany

\begin{abstract}
Purpose - How can social presence, participation and a sense of community be formed in an online setting without compromising on social connectedness through physical distancing? Under consideration of the goals for an Education for Sustainable Development, transformative science and the social techniques of Theory $U$, developed by Otto Scharmer (2016), an online Community of Inquiry of researchers, practitioners and learners was to be developed, followed and observed to discuss the question whether and how it was possible to create an awareness-based, future-oriented and socially committed online community that would enrich social transformation processes.

Design/methodology/approach - Methods of 1st, 2nd and 3rd person research were applied, as well as group discussions, one Mentimeter survey and one standardised questionnaire with an open question.

Findings - Results indicate that it is not only possible to create a feeling of community in an online setting, but also point to the terms and conditions which act as enablers and influencers, like seeing each other faceto-face, collective check-ins and check-outs as well as small group break-out sessions. Video conferencing and the practicing of rules of conduct and communication, also referred to as netiquette, enable a transcendence of the physical distance to reach a feeling of belonging and social presence in the perception of the participants.

Originality/value - In line with global sustainable development, the study also sets an example for how to reduce personal emissions when planning an international conference. Also, it shows how to create online spaces to connect people worldwide, which will support to take over responsibilities as world citizens.
\end{abstract}

Keywords Community engagement, Online community, Online presence, Online interaction, Online learning, Online collaboration, Transformation, Online social connectedness, Theory U, Community of inquiry,

Sense of community, Video conferencing

Paper type Research paper

(C) Felix Westermann, Linda Doll, Maren Duprés, Sofia Späth and Petra Monika Schweizer-Ries. Published in Journal of Work-Applied Management. Published by Emerald Publishing Limited. This article is published under the Creative Commons Attribution (CC BY 4.0) licence. Anyone may reproduce, distribute, translate and create derivative works of this article (for both commercial and noncommercial purposes), subject to full attribution to the original publication and authors. The full terms of this licence may be seen at http://creativecommons.org/licences/by/4.0/legalcode

Special thanks goes to the German Academic Exchange Service, which made it possible to finance this study and to the Digi-School team for holding the learning space, the several experts from Germany and Spain who enriched the intercultural learning, and last but not least, to the students who patiently supported the authors' research endeavors and expressed openly, how they felt and what they learned in the intercultural-online-course.

Conflict of interests: The authors confirm no conflict of interest in the development and process of research.

Funding: This study was funded by the German Academic Exchange Service under the Project-ID 57514250 and the title "ESD - fair and ecological production, consumption and distribution of olive oil".
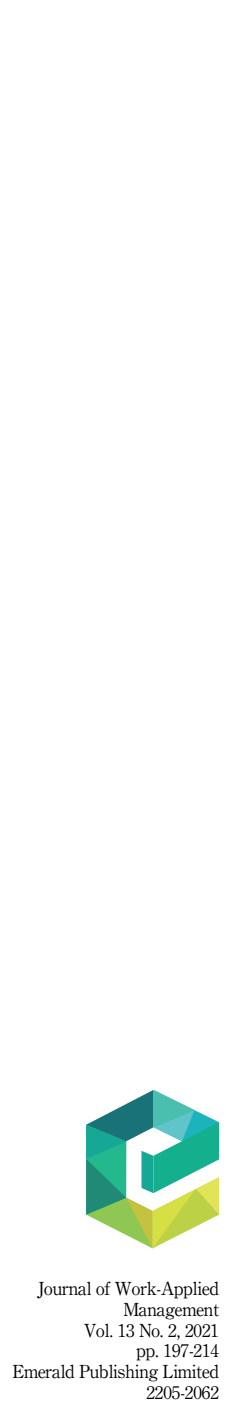
JWAM

13,2

198

\section{Transformative education and collaborative social learning}

The global COVID-19 pandemic posed huge challenges to wide structures of social systems, including the educational system. Physical face-to-face classroom seminars had to move to the online environment. Likewise, international conferences and meetings had to be replaced by video-conferencing formats. From the perspective of sustainability and transformation studies, this creates new opportunities to gain knowledge in the field of online education, the creation of online awareness, and the development of an online meeting culture, with the advantage of saving $\mathrm{CO}_{2}$, while being able to connect worldwide. Placed in a transformative educational context, the main questions to arise are how to empower participants to feel socially close, to collaborate and to experience a sense of community while being geographically apart. With the goal of reducing personal emissions, shifting occasional conferences, meetings or classes to the online environment, might introduce new ways of interaction and collaboration. Not only locally but also in international contexts, this can provide new spaces for human engagement, the feeling of social closeness, and the acknowledgement of personal responsibility for one's actions.

Sustainability science is facing the task, to discover new ways of gaining and making use of knowledge to tackle the complexity of todays' global challenges (Lang et al., 2012). While this does not only apply to the area of research, it is equally important to prepare students to become future change agents by applying reflective, action- and responsibility-focused methods of a transformative education (Fraser, 2015; Frisk and Larson, 2011; Jacobi et al., 2016; Leal Filho et al., 2018; Schneidewind et al., 2016).

In a more general sense, Biesta (2004) proposes a new "language" or understanding of how education is interpreted by educators, learners and education institutions. Instead of prescribing certain learning outcomes, learners should negotiate and critically reflect which learning outcome is individually useful and practical. Mostly neither educators nor students know in advance, what the actual result of a learning process may look like. The learning outcomes are as individualistic as the learners itself and by engaging in mutual learning, students can learn about their subjective meaning, influence and responsibility in their own learning process, as well as in the learning processes of others. In contrast to a traditional learning context, in which students are supposed to acquire already built knowledge constructs, transformative social learning contexts strive to empower a learner's ability and willingness to self-construct an individual meaning and understanding of new knowledge fragments. Thereby participants reflect on their personal values, that simultaneously influences the way in which they make use of their novel, individual meaning perspectives (Whitehead, 1989).

One methodological aspect is the focus on the social co-production of a collective understanding of complex societal challenges in sustainable development in a transdisciplinary and transepistemic context (Schweizer-Ries and Perkins, 2012). In sustainability education, the concept of social learning receives wide recognition. It refers to "the collective action and reflection that occurs among different individuals and groups as they work to improve the management of human and environmental interrelations" (Keen et al., 2005, p. 4). Picking up the aspect of collective engagement, the definition highlights that sustainable development is a result of the purposeful interaction between groups or individuals with different backgrounds yet shared intentions. Collaboration is, therefore, a key element in social learning and is reciprocally built upon action, reflection and the willingness and ability to take over responsibility (Källström and Ljung, 2005). To be able and willing to take on responsible behaviours towards sustainable actions, learners need to acquire the skill to acknowledge and negotiate alternative perspectives on individual and on collective levels, that are existent in social and environmental systems (Keen et al., 2005).

For social learning to be considered an effective way of teaching sustainability awareness and practice, simply embedding the learning environment in social contexts is not sufficient. 
Rather, it must take into account a change in awareness by individuals and wider social units (Reed et al., 2010). Practical examples and tools for how these learning skills can be integrated into Higher Education courses do already exist and are currently being further researched (see, e.g. u.lab-community in Bajraktari et al., 2016; Iser and Schweizer-Ries, 2021; Pomeroy and Oliver, 2018; for tools Scharmer, 2021).

An emerging question therefore is how this can be supported online with physical distancing.

\section{Face-to-face learning in the online classroom}

So far, video conferencing in online learning environments was often seen as a poor substitute for the experiences and advantages a physical classroom might offer (Pianesi and Lenzo, 2011). However, with the outbreak of COVID-19, educational institutions were forced to rely on the online environment for most of their activities, including teaching. Depending on which form of interaction and participation between students and teachers is chosen, asynchronous or synchronous formats can lead to the development of different learning skills (Hrastinski, 2008). To provide rich classroom-like experiences in the digital space, setting the right social climate in an online learning environment and providing space for collaboration and interaction has an influence on students' satisfaction and perceived learning outcomes (Ascough, 2007; Garrison and Arbaugh, 2007; Paechter and Maier, 2010). More than a physical classroom-setting, online instructors need to make sure that learners feel welcomed, acknowledged and safe to present themselves to an online audience, decreasing the chances for students to feel isolated or lonely (Delahunty et al., 2014; Pigliapoco and Bogliolo, 2008). Also, well-structured content and clear expectations were found to be important for online students (McBrien et al., 2009). Especially in online teaching, synchronous formats with video-conferencing techniques have been found effective and engaging (Berry, 2019; Brown et al., 2016; Fatani, 2020; Lindgren and Leblanc, 2013; McBrien et al., 2009). However, when it comes to building socio-emotional relationships, the physical classroom-setting is still favoured (Paechter and Maier, 2010). In contrast to online communities, physical classroomcommunities oftentimes form themselves without much aid by teachers (Oliver et al., 2007). But will these assumptions change when students can connect face-to-face and with additional support of the instructor?

\subsection{Sense of community}

The term sense of community $(\mathrm{SoC})$ is referring to a situation in which students feel socially and emotionally connected to their peers and fellow community members. It has been defined as "a feeling that members have of belonging, a feeling that members matter to one another and to the group, and a shared faith that members' needs will be met through their commitment to be together" (McMillan and Chavis, 1986, p. 9). Therefore, it reflects an "emotional response to relationships between group members" (Delahunty et al., 2014, p. 12).

Studies that measured whether and how much influence physical distance has on a $\mathrm{SoC}$ came to different conclusions. While some found a higher rate of $\mathrm{SoC}$ amongst students attending physical classroom lectures (Drouin and Vartanian, 2010; Rovai et al., 2005), Exter et al. (2009) and Pigliapoco and Bogliolo (2008) could not find significant differences between online and physical face-to-face settings. Rovai (2002) identified four dimensions of a classroom SoC: group spirit, trust, interaction and commonality of the learning experience and suggested that it can lead to more satisfaction and an increased learning success amongst students (Tsai et al., 2008). Raising socio-emotional trust, e.g. by increasing communication, engagement, and interaction between participants in online courses (Berry, 2019; Delahunty et al., 2014; Drouin and Vartanian, 2010), as well as making use of a range of technical participation methods such as break-out rooms, polling features, the chat function, 
JWAM

13,2

200

virtual drawboards or the hand-raising tool in video-conferencing formats (Brown et al., 2016; McDaniels et al., 2016), can lead to an increase of $\mathrm{SoC}$.

\subsection{The community-of-inquiry framework and Theory $U$}

The Community-of-Inquiry framework (CoI) can be seen as a framework and guide for the research and work with online learning communities (Garrison and Arbaugh, 2007). It consists of three forms of presence that constitute the online learning experience: social, cognitive, and teaching presence. While all presences are interrelated, there is growing evidence that teaching presence is most effectively mediating the two other forms and provides a strong determinant of the quality of the online learning experience (Garrison et al., 2010). As the momentum of the COVID-19 pandemic forced a majority of universities and schools to shift education to the online environment, teaching presence became even more important than before (Rapanta et al., 2020).

Theory $U$ is a self-awareness-based change and transformation theory and social technology (Scharmer, 2016). It builds upon a collaborative process along the sides of an "U"-shaped framework, where transformational dialogue (Drimie et al., 2018) in the form of non-judgmental listening and authentic communication (cf. Figure 1) are supposed to lead to a state of presencing. Presencing, which is a combination of presence and sensing, describes the situation when someone is cognitively and emotionally fully present not only in front of another person but in unity with the other persons. It is the baseline to the right wing of the $U$, for co-creating an emerging future for systems that put the collective well-being before singular interests (Scharmer and Kaufer, 2013). Therefore, getting down to the state of presencing requires social and cognitive presence.

Social presence covers the aspects of feeling welcomed and safe to present oneself to others and to have the intention to build meaningful relationships to the groups' members. Cognitive presence is defined as "the exploration, construction, resolution and confirmation of understanding through collaboration and reflection" (Garrison, 2007). Shea and Bidjerano (2009b) found that respondents who felt a SoC also scored higher in their level of cognitive presence, while social presence in turn is considered a positive influence for a $\mathrm{SoC}$ (Rovai, 2002). The totality of all relationships that have an influence on the cognitive, communicative and action processes within a community or group is what Scharmer calls a social field (Scharmer, 2016). The extent of $S o C$ therefore is a mean to measure the quality of the social field and its underlying socio-emotional interactions.

Figure 1.

Levels of conversations according to Theory $\mathrm{U}$
Speaking from what they want to hear

Polite routines, empty phrases

Conforming: not saying what you think

Speaking from what I think

Divergent views: I am my point of view Confronting: saying what you think

Speaking from seeing myself through the eyes of another as part of the whole

From defending to inquiry into viewpoints Self-reflecting: reflecting on your part

Talking reflectively

4. Collective Creativity: Speaking from collective presence, from what is moving through

Talking transformatively

Intentional stillness, presencing, flow Co-creating: profound shift: authentic self

Source(s): Scharmer (2015) 


\section{Research interest and background}

How such an online community-building process can be turned into practice was part of an intercultural Digi-School, which took place in the winter semester 2020/2021. The format of the Digi-School was initially planned as an international summer school. However, due to the global pandemic situation, the concept had to be adapted to an online format, providing the chance to find out, how this format can help to connect without traveling. Generally, the concepts of summer schools have the advantage to represent a welcoming addition to the regular lecture-schedule of a university (Frey and Mehrabi, 2020), offering perfect opportunities for interdisciplinary and transdisciplinary research and project work for students within a fraction of a semester's time.

Since nearly all lectures and seminars were held online during the COVID-19 pandemic, the question emerged whether and how it was possible to create a digital space for integration, collaboration, and exchange between students, practitioners, and researchers, while simultaneously creating a feeling of social connectedness. Thus, the following research questions were developed:

(1) Can an intercultural SoC be built in online settings?

(2) Did participants experience a deep social connectedness albeit the physical distance?

(3) Which are enablers or challenges to this?

Initially planned as a daily, 10-days-program in Andalusia, Spain, the Digi-School was integrated into the regular winter semester program and extended on weekly meetings in face-to-face web-conferences. The experience and perception of presence and a social connectedness was surveyed after each session.

\subsection{The course's concept}

The Digi-School followed a project-based participatory and collaborative social learning methodology (Ernst, 2019) to increase personal, social and environmental awareness of all participants and to create a $\mathrm{SoC}$ between students and local experts. The participants learned about sustainability, regenerative agriculture, and its awareness-raising, as part of the project SustOlive, in which the olive oil acts as a medium to communicate sustainability and to raise consciousness about individual consumer decisions. The Digi-School sessions regularly took place on Tuesdays for the duration of three hours on average and were held via the video conferencing platform Zoom. Each session was structured differently in content and methodology, which ensured high diversity to attract the participant's attention. Collaborative activities included continuous group work, where participants worked independently in small groups in break-out sessions and in-between the joint sessions. Additionally, the participants learned from different field experts, who joined the groupmeeting at times. Students prepared expert interviews to discuss and exchange ideas and knowledge with professionals. Depending on the expert's language skills, the seminar language was either German, English or Spanish. Translations from Spanish into German or vice versa took place via the chat function.

Referring to the "language of education" from Biesta (2004), the courses ultimate learning objective was not that of specific skills, but rather the reflection on an individuals' mindset towards their role as learners for themselves and for the greater social good.

\subsection{Netiquette}

To ensure equal recognition of all participants and respectful interaction, an online code-ofconduct (netiquette) has been communicated at the beginning of the Digi-School. The rules included: (1) being on time when the meeting starts, (2) focusing on the meeting only,
Create human spaces in online communities

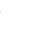


JWAM

13,2

(3) keeping the webcam on during the entire online meetings, (4) active participation during each meeting, (5) spending breaks not in front of the screen but doing "real" breaks and (6) expressing a collective farewell to the group when leaving the meeting.

Each session was opened with a check-in, where the students shortly told their peers how they were presently feeling and what they were looking forward to or being curious about in the present session. At the end of each session a short check-out round summarized the experiences, insights and remaining questions after the session. The role of the instructor was defined as a coach and a facilitator to foster a welcoming environment for open participation, basic structure, and demonstration of flat hierarchies. The goal was to form a trustful and transparent atmosphere, where learning occurs by listening and interacting with one another as opposed to a less meaningful and passive audience interaction. Constructive feedback was an essential building block for the project and the Digi-School itself. The purpose of feedback was to improve the learning process. Feedback was given after each session by all participants.

\section{Research methodology}

A mix of methods was used to assess the perception, development and future possibilities of online collaboration and awareness - raising on the topic of sustainability in a digital learning environment. For the sampling and evaluation of data, 1st-, 2nd- and 3rd-person research was used (Reason and Torbert, 2001), supplemented by the analysis of a standardized online questionnaire. Data for the 1st-, 2nd- and 3rd-person qualitative research was sampled via personal written reflections of individual participants (1st-person) and online discussion groups (2nd-person). Results from the 1st person-reflections and 2nd-person online discussion groups merged with the 3rd-person investigations (observation and survey). To gather final information about the perceived group characteristics that formed during the Digi-School, a Mentimeter-survey at the end of the Digi-School was used for the 3rd-person evaluations as well.

While 18 students between 22 and 32 years registered for the Digi-School, not all completed the online-surveys, providing a range of responsiveness between 7 and 16 participants. The questionnaire included 12 self-constructed items measured by selfassessment on a scale of one to seven and one open question. It was sequenced into three broad fields: awareness about regenerative agriculture, communication according to the U-process, and the perception of the sessions' quality for online conferencing compared with imagined offline events as an open question. Because of its "epistemic engagement approach, which foregrounds the role of learners as collaborative knowledge builders" (Shea and Bidjerano, 2009b), the CoI-model was chosen as a second underlying framework besides Theory $U$.

For the online survey, all 18 participants were expected to fill out the online questionnaire each week. However, due to absences in the group and the fact that not every item of the questionnaire was answered, a mean responsiveness rate of $81.49 \%$ was reached. In total 108 questionnaires were distributed over a time frame of 11 sessions. Participants of the survey were all female and registered students at the University of Applied Sciences Bochum, Germany, or the University of Córdoba, Spain.

\section{Findings}

Analysis of the 14 personal-reflections [RF], two online discussion groups [DG], the Mentimeter-survey $[\mathrm{MM}]$ and the open question from the online survey $[\mathrm{OQ}]$ revealed that the results can be categorized into two broad areas to assess and measure the formation of the online learning setting: (1) the course environment and social field development, forming a 
SoC and (2) communication and interaction within the group. In the following sections, results will be introduced using the two categories from which conclusions for the research questions are drawn.

\subsection{Course environment and social field development}

Participants agreed that the check-in-phase at the beginning of each session contributed to setting a positive, trustful atmosphere and getting in touch with the fellow course members. Especially the fact that members were encouraged to honestly answer and personally inquire about the well-being of their peers, supported them to build meaningful and trustful relationships. It was acknowledged that to open up was a process that needed time as one participant mentioned: "For me, it was a process of getting to the point of really consciously and honestly answering the question 'How are you?' (if the framework fits). I can well imagine that for some it is unfamiliar and that this is simply a learning process, that does not happen overnight" [RF7]. Participants also experienced more authenticity and were relieved by not having to pretend that they are always fine [DG1].

When course participants were asked directly about which characteristics of the group drove their $S o C$, openness and affection were amongst the most frequently mentioned motives [MM2]. Furthermore, participants agreed that a significant contributing factor was the positive appearance and expression by the course leader, which increased their motivation and perceived performance in the course: "The project leader radiates a positive charisma which increases motivation and overall performance during the online session" [DG1]. Other participants enjoyed the personal greetings of the course leader, when participants enter the digital room [DG1], thus creating a welcoming atmosphere and further contributing to an overall good working climate. The flat hierarchy that was applied by the leader positively influenced the perceptions of course climate [RF3], providing the base for socially equal interactions.

Diversity in course methodologies and culture was another positive source of motivation for the overall course atmosphere. Participants felt that "because of the wide range of different people, topics and methods, every session was very interesting" [RF9]. However, active participation was perceived to be difficult when no clear structure or agenda was given despite high information density. Participants agreed that "a clear organizational structure (when is the break? Until what time is the lecture? What is on the agenda?) and rituals (at the beginning 'arriving' in breakout rooms, at the end providing opportunities for questions or organizational matters)" [RF2], helped their orientation and concentration during the course sessions. The application of the netiquette generally received positive remarks. Its intuitive application by all participants facilitated the formation of a welcoming and respectful atmosphere, interaction, and the integration of all group members.

Some aspects were regarded as harmful for the individual level of comfort during the group meetings. The constant use of the webcam was a big challenge, especially for participants who could not change rooms during breaks. Other reasons for not wanting to permanently stream their video ranged from having health issues forcing frequent movement in the room, fear of getting a worse grade if the camera was switched off for a while, and being distracted by the thought of how one may appear to others via the screen [DG1]. Further it was noted that it may have harmed the right of privacy. The instructor recognized the issue noting that "this 'privacy' (participating from home) helps the opening process, but also seems to create insecurity, inconvenience, desire for protection (protection of privacy) . . . also desire for freedom, freedom in the seminar to also do something else (. . .) 'on the side' (. . .) which helps to concentrate, such as knitting (...)" [RF6]. One participant added that after busy sessions it has been difficult to rest one's mind in the same room where before many people were "present" [DC2]. This highlights the need for a protective space when private and professional life
Create human spaces in online communities

203 
JWAM

13,2 merge in the same place. A suggestion that was made by one participant was that the rules concerning the use of the webcam were formulated collaboratively to take individual needs into account.

\subsection{Communication and interaction}

Participants favored the open and encouraging approach by the course leader to participate in discussions, by which they felt more directly addressed than in other courses. Both is best reflected by the two quotes: "What is important to me in digitallearning: encouragement by the instructor to join in discussions, use the microphone, and let discussions arise" and "Personally, I participated more than usual in the digital format because I felt more directly addressed" [RF2]. The instructor of the Digi-School also felt that engagement in the online environment seems to pose reduced barriers to more quiet students than the traditional classroom setting. This might be due to more privacy and security by the home setting but also due to the proactive role of the course instructor, strengthening the central role of teaching presence. Above all, giving a voice to every member of the group was a significant contributing factor to feel a $\mathrm{SoC}$. This could be observed in a reflection about the way of life of some of the local farmers in Andalusia, who were invited to introduce their concept of community-life in one of the sessions: "The way of life of the people has made a lasting impression on me. I find it amazing how conflicts are prevented by giving everyone a voice within the discussion groups. I think it is exactly this feeling of community and being heard, that many of us are missing" [RF8].

At the end of the Digi-School participants were asked to name characteristics that would best describe their group. Frequently mentioned was an open, communicative, and cooperative style. One possible explanation may be the alternation between plenary discussions and group discussions in break-out rooms, facilitating a more personal interaction and relationship-building. However, during a group reflection process, participants wished for even more small group assignments to build even more trustful and personal relationships with their fellow students. The use of the webcam was a positive factor, allowing also for non-verbal communication to take place. This feature particularly seemed to offer a distinctive character to the course. One participant concluded that she liked "having the camera on and seeing the faces of my fellow students during discussions" [RF2] while others added that it helped "simplifying personal interaction in the digital room" [DG1]. This indicates, that it is possible to reduce the perceived transactional distance commonly attributed to the online environment (Wicks and Sallee, 2011).

Nonetheless it was observed that via the screen not all forms of verbal and non-verbal communication can be transmitted. In the peer reflection process, it was widely agreed, that as many advantages as the online format might generate, it also has its downsides. The highest sacrifice might be the missing of direct, personal interactions and natural spontaneity which leads to a less natural exchange with other participants [DC1]. One of the experts who was invited to join some of the sessions remarked that "for communication regarding the exchange of information I am missing the physical proximity to feel something. I am sitting in front of my screen alone and I cannot sense a group, there are no sounds, no mimics, no smellseverything is dead and technical. Sometimes, the pictures of single persons are switched on, then we have something like an interaction, but not as a group but as a more or less moving single picture and a microphone voice" [RF11].

It is questionable whether this might not also be a factor influenced by age and experience with digitalization in general, as one of the invitees explained: "However I am old, and oldfashioned! I always prefer a hands-on situation - to me it seems more human" [RF12]. On the other hand, another of the older experts from Spain expressed that "It is very strange because [...] I do not like very much the Zoom environment, because I think it is very distant. But I was thinking right now that I had really the sense of community together. [.. .] I do not know why, but 
it is like ... magical, because I feel us like, or we are like a community or like a group. It's the first time [...]; it was very nice to experience" [RF15].

Besides facilitating personal interaction and (non-)verbal communication, the use of the camera was also preferred when creating a more dynamic and engaging feeling of closeness. Several participants agreed on statements such as "Personally, I really enjoyed the sessions in which we visited places digitally (. . .). I think this active way of not only talking, but also showing the participants around has brought a very special dynamic to the Digi-School. In my opinion, these sessions have brought us together as close as it is possible virtually" [RF9]. Another participant strengthened this impression by stating that "of course, it's different to be on site yourself, but I find that a digital tour like this brings a completely different feeling than, for example, just looking at photos" [RF4]. It turned out that it is not only important to be connected through the human relationship side, but also through the dynamics of the different locations from which participants streamed their video, which had to be interpreted by the participants to resemble an idea of what their sensory experiences on site might have been like.

A well-documented impression of this need is the comment by one of the experts from Spain: "We are also missing out on meeting in different surroundings which could support and emphasize the reunion. It is also true that we are missing some of our senses in digital reunions, such as smell. In a meeting with emphasis on sensorial discovering, this could be an obstacle" [RF10].

Another obstacle that was frequently mentioned and that seemed to build a barrier between participants and fellow group members, was the languages spoken during the meetings. The mix of German, English and Spanish and its simultaneous part-wise translation in the chat was overwhelming for some of the non-native speakers. Participants with a lack of knowledge in some of the languages sometimes felt they "lagged behind a bit compared to the others" [RF1], causing major concentration and motivation problems. One comment from the open question in the online survey explains: "Unfortunately I could not follow so well due to the three different languages that were spoken or translated in the chat. On site I would certainly have noticed the context even in Spanish, but via zoom unfortunately I switched off quite quickly because the various channels overwhelmed me" [OQ2]. Thus, the language barrier imposed a triple-fold problematic issue: Firstly, the primary lack of understanding and finding meaning of what others have said. Secondly, the lack of socioemotional relationship building. Thirdly, the fading state of presence due to the loss of focus of attention. Sometimes, poor Wi-Fi-connections caused further stress on the ability to understand one another and decreased the ease of building socio-emotional connections.

\subsection{Summarized results of the standardized online survey}

The primer motivation of the online survey was to assess the process of the course group through the $U$-process in each session and over time. Further focus was laid on the awareness building of the students about regenerative agriculture and olive oil along the course. Due to the missing normal distribution, non-parametrical statistics had to be used. Additionally, missing values and missing students in some of the lectures made it more difficult to process the analysis. Figure 2 shows the overall means of all items along the measured sessions.

There is a significant positive correlation between the questions describing the $U$-framework ( $\rho=0.408$ to $\rho=0.745 ; p<0.01$, cf. Figure 2 , questions 6 to 11) [1]. This confirms that the levels of communication according to Theory U are associated to the state of presencing, where intentions and inner connections are shared between the individuals. Furthermore, there exists a statistically significant positive correlation between the progress of the Digi-School and the knowledge of the students on olive oil $(\rho=0.422, p<0.01)$ and sustainable forms of agriculture $(\rho=0.447, p<0.01)$. However, no significant correlation
Create human spaces in online communities 
JWAM

13,2

\section{6}

Figure 2.

Results and progress of online survey

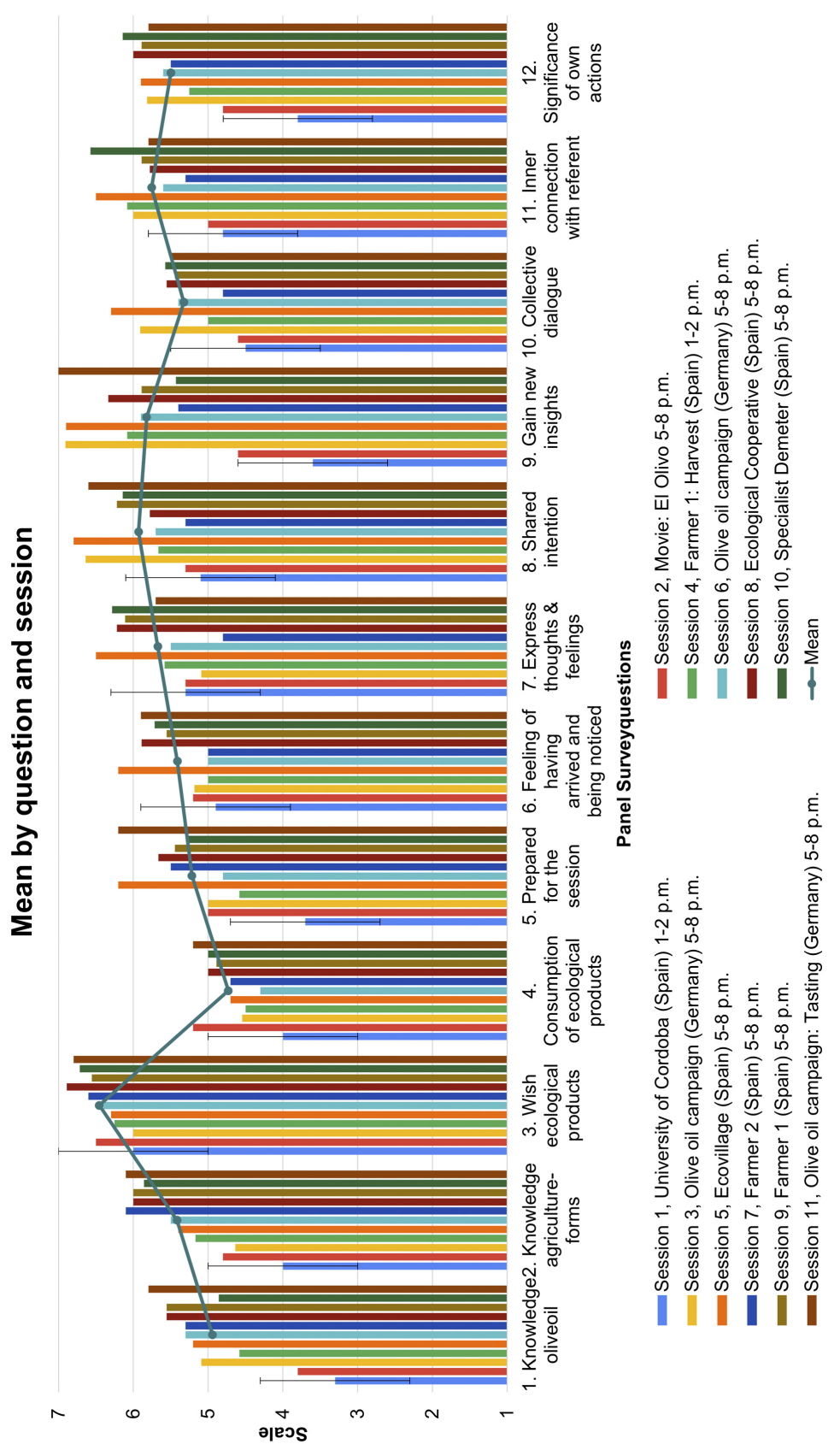


between the progress of the Digi-School and the questions concerning the $U$-progress were observed. This shows that knowledge builds on time, while deep inner connections and a common flow of thought, which Theory $U$ aims at, do not necessarily increase by time. This may also depend on the individual parameters of a session, such as the referent, language, and the chosen topic of a session. As shown in Figure 2, one exceptional example is Session 5, in which all questions relating to the $U$-framework reached above average mean scores between 6.2 and 6.9 (highest 7). A special character of this session was the dialogue about experiences and feelings related to the topics of conflict management and solidarity, which enabled the participants to get deeply involved not only into the sessions' topic but also into the levels of communication according to Theory $U$.

Another statistically significant positive correlation is between when students realized the relevance of their actions concerning the specific topic of the session and their sense of connection to the sessions' referent $(\rho=0.557, p<0.01)$. In addition, it was important, that the students felt connected by a common intention $(\rho=0.507, p<0.01)$ [2]. It therefore can be assumed that joint emotional connections were associated with an individual feeling of responsibility for the topic of a session. Shared opinions from the Mentimeter-survey further accentuated that common interests, intentions and goals between the group-members contributed to their $\mathrm{SoC}$.

All in all, this resulted in a reported average score of 5.78 (highest 7 ), when students were asked about whether they experienced a SoC during the Digi-School (MM3). In total, six students strongly felt as part of the group whereas only three students felt a medium strong connection to the group.

Results from the 59 responses to the open question assessing the perceived suitability of the session for online teaching and possible imagined differences to a physical face-to-face meeting, showed some difficulties with the online teaching format. In contrast to the expectations, the answers accentuated a positive absence of expected technical difficulties. Yet eleven comments expressed a belief that the web-conferencing environment might still not achieve the same level of interaction and exchange amongst students than the physical face-to-face setting. What was missing most were the more intense experiences of senses like touch, taste, smell, and a broader vision of contextual factors, meaning those experiences which cannot be grasped by the camera. Yet, via a synchronous and expert-led olive oil tasting (Session 11), where every participant got their own personal tasting package home-delivered, the issue of lacking sensual experiences could partly be overcome. Indicated by a total mean rank of 7 out of 7 in new knowledge gaining (see also Figure 2), a novel experience to all participants was provided. This shows that even selected sensory, in this case, gustatory and olfactory, learning experiences can be transmitted via online groups.

Furthermore, seven students desired a clearer structure and more breaks when meeting online. Participants stated that the duration of up to three hours attentive listening in front of the screen was tedious at times. Despite the fact that the open question was asking for a negative comparison of the experienced online session to an imagined physical meeting, eleven students positively confirmed that they did not experience the online format as inferior to a physical face-to-face meeting.

\section{Results summarized}

The research questions can be answered in the following way: It can be confirmed that the online environment could equally provide the opportunity to build a $\mathrm{SoC}$ like in physical face-to-face classroom settings. Mainly positive experiences have been reported by the study group and their Mentimeter-rating on the perceived $S_{o} C$ during the Digi-School was very high. Most of the participants of the Digi-School did feel a deep social 
JWAM

13,2

connectedness to the group. In a general sense this was expressed in their Mentimeterrating and in a wider sense also in the personal reflections [RF]. Only three of the students reported in the Mentimeter-survey, that they felt only somehow, but not very much connected.

Furthermore, some students expressed that they desired more time for relationship building. Although they felt a SoC, they also felt that a physical face-to-face meeting would probably have provided more profound experiences of social connectedness.

Enablers to form a $S o C$ online were identified in: (1) making use of the webcam to see the faces and surroundings of the other group members, also facilitating forms of non-verbal communication and the overall experience of being mutually present in the web-conferencing environment, (2) the check-in phase with the personal inquiry and the resulting formation of an authentic and trustful social field and (3) the support in community building processes and facilitation of interactions that were provided through the teaching presence. Barriers were identified in the different demands of the students, especially in terms of desires for more privacy and structure during the online sessions. Also, the use of different languages sometimes caused difficulties to some of the students, especially in sessions where native languages were spoken that not all participants could understand without further translation.

\section{Discussion}

The goal of this paper was to find out how a deep and meaningful sense of Community (SoC) can be developed in a distant university course focused on social and ecological sustainability, and which factors may facilitate or impede the formation of a $\mathrm{SoC}$ by a web conferencing format. Results from this study suggest, that it is not only possible to create a $\mathrm{SoC}$ online, but that the web conferencing format is a distinctive feature that helped the process. Just like McDaniels et al. (2016), this study argues that online education must not be less personal than physical face-to-face courses. Nearly all participants of the course felt integrated into the group, though most have never met in the same physical space before. Besides using the web conferencing format, three aspects set themselves apart as being facilitators in the process: (1) becoming socially present in front of the screen with all other participants simultaneously, (2) interacting with one another in discussions and online conversations and (3) building open, authentic, and trustful spaces for communication and sharing of personal experiences. Consequently, the study can confirm prior theories on building a $S o C$ such as that of Rovai (2002). In his research, $S o C$ can be defined by the aspects of spirit, trust, interaction, and commonalities. All four could be identified in the study group. Group spirit formed by common topics and goals, represented by learning about regeneratively and fairly produced olive oil, the positive and open course climate, and the ability to recognize others through the use of the webcam. Trust was built by open and authentic communication of all course participants, including the course leader and external experts. This led directly to a deep socio-emotional interaction that still did not miss out on task orientation, as the group also described itself as having experienced an active, engaged, informative and productive time, in which members were generally seen as equally motivated to participate in the course. Commonalities were formed by the common topics and interests that were shared by the group as well as the sharing of personal experiences, feelings, intentions, and goals. This proves the study of Hoinle et al. (2021), in which the socioemotional relationship dimension and collective decision-making processes between university and non-university participants of transdisciplinary learning spaces are highlighted as crucially important for the success of cooperative and transformative teaching spaces.

Further evidence can be provided for the influencing factors of: (1) transactional distance, (2) social presence, (3) social equality, (4) small group activities, (5) group 
facilitation, (6) teaching style and (7) community size, which were also identified by Rovai (2002). In line with Falloon (2011b), this study would argue, that transactional distance can be effectively reduced by using video-conferencing formats for online teaching, and thus simultaneously facilitate social presence. Additionally, the check-in and check-out phases in each session led the group to collaboratively reflect upon their experiences, increase social presence, and to nurture the social field (Scharmer, 2016). The perceived course environment and climate formed during the Digi-School can further confirm the five facets of social presence that need to be established according to Sung and Mayer (2012). Social equality was perceived to be reached by the application of netiquette-rules, flat hierarchy in the course, and by encouraging each student to actively participate in the sessions, especially in the check-in and check-out phases. The frequent mix of break-out sessions, plenary discussions and other interaction methods not only added variety to the teaching style of the course but also fostered relational processes in the group through small group activities.

From a broader perspective, the Digi-School modelled and encultured values like trust, openness, and authenticity by setting these values as a framework for the context, and therefore, as a point of orientation for individual learners. Each participant was invited and motivated to reflect on their individual mindset and behavior towards these values and to consider what meaning might lie in making each of these values a virtue. The successful application of this approach strengthens Biesta's (2004) and Whitehead's (1989) argument that an individual's knowledge construction should not be seen from an instructional point of view, but of that from a reflective, self-constructed, and personal value based meaning perspective. Referring to the suggested fundamental educational virtues of trust, responsibility and coming into presence as unique and individual beings (Biesta, 2004), students were empowered to consider their unique role in the social process of mutual learning.

Overall, the study can confirm the importance of recognizing at least three forms of presence when planning for an online teaching format. The use of the CoI-framework was a helpful tool for which further evidence can be provided, with the aim to argue for the importance of teaching presence as a basis for the proceeding forms of social and cognitive presence (Garrison et al., 2010; Shea et al., 2006). All three forms of presence were successfully implemented and are reflected in the findings. Social presence was reached via the socioemotional relationships and the welcoming and trustful course climate, while cognitive presence could also be measured through the increased knowledge gained by the students of regenerative agriculture, especially ecologically and fairly produced olive oil. Regardless of whether a transformative, constructivist, or a more direct instruction-oriented teacherstudent approach is followed, the role of the instructor is to provide for an optimal structure of the course, allowing the best possible social climate and atmosphere for learning and interaction among the students, as well as to facilitate the group communication and interaction processes. Furthermore, the findings give substance to arguments that without social presence, no true state of cognitive presence can be achieved (Shea and Bidjerano, 2009a). Thus, it is argued, that a helpful tool to achieve both states, social and cognitive presence, is the $U$-process developed by Scharmer (2016). By aiming to reach a state of presencing, both forms of social and cognitive presence become one by transcending inner sources of the self with outer sources of the wider social field. This study argues that it is essentially the dialogue between the actors and stakeholders of a system that deepens an interaction, that may lead to a collective vision for societal transformation processes (Drimie et al., 2018).

Over the course of 3 months it was observed that the participants of the Digi-School experienced a shift in focus from a personal ego-system to a wider eco-system awareness, by building new or better relations to others, by better relating to the whole system, and by better 
JWAM

13,2

relating to oneself (Scharmer and Kaufer, 2013). Not only did participants gain new knowledge about sustainably sourced olive oil, but also about themselves, as reflections in the final discussion at the end of the Digi-School revealed. Given the relatively novel character of video-conferencing in higher education, the results indicate that connecting online for creating transformational impulses is possible.

Overcoming barriers to the process of moving along the $U$ and establishing a SoC online were identified in removing any unnecessary distractions that can affect participants' communication and interaction processes in online courses, such as language barriers, the pressure to continuously keep the webcam on during a meeting, and by ensuring that the Internet connection is as convenient, secure and stable as possible. Further the need for privacy needs to be considered when planning for participation structures in online teaching formats. Though participants were generally very satisfied with their experiences of the digital course format, several students still felt that an online meeting cannot always compensate for a physical face-to-face meeting, especially when it comes to sensory perceptions and close human contact.

In conclusion, the study can further confirm several findings from previous research in the context of online conferencing in student education. Specifically, the various results of online interaction in such a format, and their mediation by teaching presence are largely consistent with experiences and recommendations found in Fatani (2020), Berry (2019), McDaniels et al. (2016), Cornelius and Gordon (2013), Lindgren and Leblanc (2013), Falloon (2011a), McBrien et al. (2009), and Ascough (2007). While comments on diversity partly reflect Gunawardena and LaPointe (2008) in their suggestions for building social presence in the social online course environment, the aspect of cultural diversity can also be found in the study of Lindgren and Leblanc (2013) where participants were able to experience "transculturality at home".

\section{Limitations and further research}

The study faced some limitations, of which the most important will be mentioned below with suggestions for further research. The first limitation was the relatively small population size of 18 participants for the qualitative and quantitative data analysis. Due to absences in almost all meetings, the planned number of responses was rarely reached. This has, of course, an impact on the absolute validity of some responses and the concluding results. Yet, further studies could look at more detail on the effect and optimal range of group size in webconferencing formats. While this study group was of comparable size to that of McDaniels et al. (2016), no negative statements were found about the group being too big for the intended purpose of online learning. Next, only the online experience could be measured but not be compared to a physical face-to-face experience of the group. Though only a few have been in the project before and went to Andalusia once to visit and meet the local cooperative experts and farmers, no overarching comparison was possible on how the initially planned Summer School might have taken place without the situation of a global pandemic. Additional studies could pick up on this topic and compare a physical face-to-face summer school and its digital equivalent to assess the formation of a $\mathrm{SoC}$ and the change in awareness among participants. Further studies should also focus on the issue of privacy in the web-conferencing format, the experience of senses on the effect of social presence and $S o C$, as well as on the effect of a netiquette on group interaction.

\section{Notes}

1. According to Cohen (1992), these are medium to strong effects.

2. According to Cohen (1992), these are both strong effects. 


\section{References}

Ascough, R.S. (2007), "Welcoming design - hosting a hospitable online course", Teaching Theology and Religion, Vol. 10 No. 3, pp. 131-136.

Bajraktari, F., Mosse, R. and Voto, G.N. (2016), "Transforming U.Lab: re-designing a participatory methodology using a strategic sustainable perspective", Master's degree thesis, Blekinge Institute of Technology, Karlskrona, available at: https://www.diva-portal.org/smash/get/diva2: 955129/FULLTEXT01.pdf.

Berry, S. (2019), "Teaching to connect: community-building strategies for the virtual classroom", Online Learning, Vol. 23 No. 1, doi: 10.24059/olj.v23i1.1425.

Biesta, G. (2004), "Against learning: reclaiming a language for education in an age of learning", Nordisk Pedagogik, Vol. 24 No. 1, pp. 70-82.

Brown, B., Schroeder, M. and Eaton, S.E. (2016), "Designing synchronous online interactions and discussions", Proceedings of the IDEAS: Designing for Innovation, pp. 51-60.

Cohen, J. (1992), “A power primer”, Psychological Bulletin, Vol. 112 No. 1, pp. 155-159, doi: 10.1037/00332909.112.1.155.

Cornelius, S. and Gordon, C. (2013), "Facilitating learning with web conferencing recommendations based on learners' experiences", Education and Information Technologies, Vol. 18 No. 2, pp. 275-285, doi: 10.1007/s10639-012-9241-9.

Delahunty, J., Verenikina, I. and Jones, P. (2014), "Socio-emotional connections: identity, belonging and learning in online interactions: a literature review", Technology, Pedagogy and Education, Vol. 23 No. 2, pp. 243-265, doi: 10.1080/1475939X.2013.813405.

Drimie, S., Hamann, R., Manderson, A.P. and Mlondobozi, N. (2018), "Creating transformative spaces for dialogue and action: reflecting on the experience of the Southern Africa Food Lab", Ecology and Society, Vol. 23 No. 3, doi: 10.5751/ES-10177-230302.

Drouin, M. and Vartanian, L.R. (2010), "Students' feelings of and desire for sense of community in faceto-face and online courses", Quarterly Review of Distance Education, Vol. 11 No. 3, pp. 147-159.

Ernst, A. (2019), "Review of factors influencing social learning within participatory environmental governance", Ecology and Society, Vol. 24 No. 1, doi: 10.5751/ES-10599-240103.

Exter, M.E., Korkmaz, N., Harlin, N.M. and Bichelmeyer, B.A. (2009), "Sense of community within a fully online program", Quarterly Review of Distance Education, Vol. 10 No. 2, pp. 177-194, Article ISSN 1528-35 (Perspectives of Graduate Students).

Falloon, G. (2011a), "Exploring the virtual classroom: what students need to know (and teachers should consider)", MERLOT Journal of Online Learning and Teaching, Vol. 7 No. 4, pp. 439-451.

Falloon, G. (2011b), "Making the connection: Moore's theory of transactional distance and its relevance to the use of a virtual classroom in postgraduate online teacher education", Journal of Research on Technology in Education, Vol. 43 No. 3, pp. 187-209.

Fatani, T.H. (2020), "Student satisfaction with videoconferencing teaching quality during the COVID19 pandemic", BMC Medical Education, Vol. 20 No. 1, p. 396, doi: 10.1186/s12909-020-02310-2.

Fraser, S.P. (2015), "Transformative science teaching in higher education”, Journal of Transformative Education, Vol. 13 No. 2, pp. 140-160, doi: 10.1177/1541344615571417.

Frey, B. and Mehrabi, F. (2020), "Die interdisziplinären summer schools an der Ruhr-Universität Bochum”, in Straub, J., Plontke, S., Ruppel, P.S., Frey, B., Mehrabi, F. and Ricken, J. (Eds), Forschendes Lernen an Universitäten, Springer Fachmedien Wiesbaden. doi: 10.1007/978-3-65830828-5.

Frisk, E. and Larson, K.L. (2011), "Educating for sustainability: competencies and practices for transformative action”, Journal of Sustainability Education, Vol. 2 No. 1, ISSN: 2151-7452, pp. 1-20.

Garrison, D.R. (2007), "Online community of inquiry review: social, cognitive, and teaching presence issues", Journal of Asynchronous Learning Networks, Vol. 11 No. 1, pp. 61-72.

Create human

spaces in online

communities 
JWAM

13,2

212
Garrison, D.R. and Arbaugh, J.B. (2007), "Researching the community of inquiry framework: review, issues, and future directions", The Internet and Higher Education, Vol. 10 No. 3, pp. 157-172, doi: 10.1016/j.iheduc.2007.04.001.

Garrison, D.R., Cleveland-Innes, M. and Fung, T.S. (2010), "Exploring causal relationships among teaching, cognitive and social presence: student perceptions of the community of inquiry framework", The Internet and Higher Education, Vol. 13 Nos 1-2, pp. 31-36, doi: 10.1016/j.iheduc. 2009.10.002.

Gunawardena, C.N. and LaPointe, D., (2008), "Social and cultural diversity in distance education", in Evans, T., Haughey, M. and Murphy, D. (Eds), International Handbook of Distance Education, Emerald Publishing, pp. 51-70.

Hoinle, B., Roose, I. and Shekhar, H. (2021), "Creating transdisciplinary teaching spaces. Cooperation of universities and non-university partners to design higher education for regional sustainable transition", Sustainability, Vol. 13 No. 7, p. 3680, doi: 10.3390/su13073680.

Hrastinski, S. (2008), “Asynchronous and synchronous e-learning”, Educause Quarterly, Vol. 31 No. 4, pp. 51-55.

Iser, O. and Schweizer-Ries, P. (2021), "Inner transition in our universities - Entwicklung digital vernetzter Lehr- und Lernräume”, in Leal Filho, W. (Ed.), Digitalisierung und Nachhaltigkeit, Springer Berlin Heidelberg, pp. 65-82. doi: 10.1007/978-3-662-61534-8.

Jacobi, P.R., de Toledo, R.F. and Grandisoli, E. (2016), "Education, sustainability and social learning", Brazilian Journal of Science and Technology, Vol. 3 No. 1, doi: 10.1186/s40552-016-0019-2.

Källström, H.N. and Ljung, M. (2005), "Social sustainability and collaborative learning", AMBIO: A Journal of the Human Environment, Vol. 34 No. 4, pp. 376-382, doi: 10.1579/0044-7447-34.4.376.

(2005), Keen, M., Brown, V.A. and Dyball, R. (Eds), Social Learning in Environmental Management: Towards a Sustainable Future, Earthscan, available at: http://www.loc.gov/catdir/ enhancements/fy1111/2005003303-b.html.

Lang, D.J., Wiek, A., Bergmann, M., Stauffacher, M., Martens, P., Moll, P., Swilling, M. and Thomas, C.J. (2012), "Transdisciplinary research in sustainability science: practice, principles, and challenges”, Sustainability Science, Vol. 7 No. S1, pp. 25-43, doi: 10.1007/s11625-011-0149-x.

Leal Filho, W., Raath, S., Lazzarini, B., Vargas, V.R., de Souza, L., Anholon, R., Quelhas, O., Haddad, R., Klavins, M. and Orlovic, V.L. (2018), "The role of transformation in learning and education for sustainability", Journal of Cleaner Production, Vol. 199, pp. 286-295, doi: 10.1016/j.jclepro.2018. 07.017.

Lindgren, C. and Leblanc, A. (2013), Development of On-Line Courses Focusing on Quality, Dalarna University, available at: https://www.academia.edu/9485601/Title_of_paper_Development_of_ on_line_courses_focusing_on_quality.

McBrien, J.L., Jones, P. and Cheng, R. (2009), "Virtual spaces and synchronous online learning", International Review of Research in Open and Distance Learning, Vol. 10 No. 3, Article ISSN: 1492-3831, pp. 1-17.

McDaniels, M., Pfund, C. and Barnicle, K. (2016), "Creating dynamic learning communities in synchronous online courses: one approach from the center for the integration of research, teaching and learning (CIRTL)", Online Learning, Vol. 20 No. 1, doi: 10.24059/olj.v20i1.518.

McMillan, D.W. and Chavis, D.M. (1986), "Sense of community: a definition and theory", Journal of Community Psychology, Vol. 14 No. 1, pp. 6-23, doi: 10.1002/1520-6629(198601)14:1<6::AIDJCOP2290140103>3.0.CO;2-I.

Oliver, R., Herrington, A., Herrington, J. and Reeves, T.C. (2007), "Representing authentic learning designs supporting the development of online communities of learners", Journal of Learning Design, Vol. 2 No. 2, pp. 1-21.

Paechter, M. and Maier, B. (2010), "Online or face-to-face? Students' experiences and preferences in elearning", The Internet and Higher Education, Vol. 13 No. 4, pp. 292-297, doi: 10.1016/j.iheduc. 2010.09.004. 
Pianesi, A. and Lenzo, A. (2011), "The art of online hosting: from powerpoint to powerful", The System Thinker, Vol. 22 No. 2, pp. 2-6.

Pigliapoco, E. and Bogliolo, A. (2008), "The effects of psychological sense of community in online and face-to-face academic courses", International Journal of Emerging Technologies in Learning (IJET), Vol. 3 No. 4, pp. 60-69.

Pomeroy, E. and Oliver, K. (2018), "Pushing the boundaries of self-directed learning: research findings from a study of u.lab participants in Scotland", International Journal of Lifelong Education, Vol. 37 No. 6, pp. 719-733, doi: 10.1080/02601370.2018.1550447.

Rapanta, C., Botturi, L., Goodyear, P., Guàrdia, L. and Koole, M. (2020), "Online university teaching during and after the covid-19 crisis: refocusing teacher presence and learning activity", Postdigital Science and Education, Vol. 2 No. 3, pp. 923-945, doi: 10.1007/s42438020-00155-y.

Reason, P. and Torbert, W. (2001), "The action turn”, Concepts and Transformation, Vol. 6 No. 1, pp. 1-37, doi: 10.1075/cat.6.1.02rea.

Reed, M.S., Evely, A.C., Cundill, G., Fazey, I., Glass, J., Laing, A., Newig, J., Parrish, B., Prell, C., Raymond, C. and Stringer, L.C. (2010), "What is social learning?", Ecology and Society, available at: http://www.ecologyandsociety.org/volXX/issYY/artZZ/.

Rovai, A.P. (2002), "Building sense of community at a distance", International Review of Research in Open and Distance Learning, Vol. 3 No. 1, doi: 10.19173/irrodl.v3i1.79.

Rovai, A.P., Wighting, M.J. and Liu, J. (2005), "School climate sense of classroom and school communities in online and on-campus higher education courses", Quarterly Review of Distance Education, Vol. 6 No. 4, pp. 361-374, Article ISSN 1528-3518.

Scharmer, C.O. (2015), "MOOC 4.0: the next revolution in learning and leadership", available at: https:// www.huffpost.com/entry/mooc-40-the-next-revoluti_b_7209606.

Scharmer, C.O. (2016), Theory U: Leading from the Future as it Emerges: The Social Technology of Presencing, Berrett-Koehler Publishers, San Francisco, California, a BK Business Book.

Scharmer, C.O. (2021), U.Lab Community Resources and Tools, Presencing Institute, available at: https://www.presencing.org/resource/tools.

Scharmer, C.O. and Kaufer, K. (2013), Leading from the Emerging Future: From Ego-System to EcoSystem Economies, 1st ed., Credo Reference; Berrett-Koehler Publishers, Boston, MA, San Francisco, CA.

Schneidewind, U., Singer-Brodowski, M., Augenstein, K. and Stelzer, F. (2016), Pledge for a Transformative Science: A Conceptual Framework (Wuppertal Papers No. 191), Wuppertal Institut für Klima, Umwelt, Energie, Wuppertal, Wuppertal.

Schweizer-Ries, P. and Perkins, D.D. (2012), "Sustainability science: transdisciplinarity, transepistemology, and action research: introduction to the special issue", Umweltpsychologie, Vol. 16 No. 1, pp. 6-11.

Shea, P. and Bidjerano, T. (2009a), "Cognitive presence and online learner engagement: a cluster analysis of the community of inquiry framework", Journal of Computing in Higher Education, Vol. 21 No. 3, pp. 199-217, doi: 10.1007/s12528-009-9024-5.

Shea, P. and Bidjerano, T. (2009b), "Community of inquiry as a theoretical framework to foster 'epistemic engagement' and 'cognitive presence' in online education", Computers and Education, Vol. 52 No. 3, pp. 543-553, doi: 10.1016/j.compedu.2008.10.007.

Shea, P., Sau Li, C. and Pickett, A. (2006), "A study of teaching presence and student sense of learning community in fully online and web-enhanced college courses", The Internet and Higher Education, Vol. 9 No. 3, pp. 175-190, doi: 10.1016/j.iheduc.2006.06.005.

Sung, E. and Mayer, R.E. (2012), "Five facets of social presence in online distance education", Computers in Human Behavior, Vol. 28 No. 5, pp. 1738-1747, doi: 10.1016/j.chb.2012.04.014.
Create human spaces in online communities 
JWAM

13,2

\section{4}

Tsai, I.-C., Kim, B., Liu, P.-J., Goggins, S.P., Kumalasari, C. and Laffey, J.M. (2008), "Building a model explaining the social nature of online learning", International Forum of Educational Technology and Society, Vol. 11 No. 3, pp. 198-215.

Whitehead, J. (1989), "Creating a living educational theory from questions of the kind, "how do I improve my practice?”, Cambridge Journal of Education, Vol. 19 No. 1, pp. 41-52, doi: 10.1080/ 0305764890190106.

Wicks, D. and Sallee, J. (2011), "Transactional distance or community of inquiry: a need for a theory of focus in online learning", available at: http://www.rus-ameeduforum.com/content/en/? task $=$ art\&article $=1000864 \&$ iid $=10$.

\section{Corresponding author}

Petra Monika Schweizer-Ries can be contacted at: petra.schweizer-ries@hs-bochum.de 